\title{
Chocolate: (un)healthy source of polyphenols?
}

\author{
Gerald Rimbach · Sarah Egert • Sonia de Pascual-Teresa
}

Received: 4 August 2010/Accepted: 9 September 2010/Published online: 30 September 2010

(C) Springer-Verlag 2010

\begin{abstract}
There is recent epidemiological evidence that chocolate consumption may improve vascular health. Furthermore, several small-scale human intervention studies indicate that habitual chocolate intake enhances the production of vasodilative nitric oxide and may lower blood pressure. It is hypothesized that potential beneficial effects of chocolate on vascular health are at least partly mediated by cocoa polyphenols including procyanidins. Based on cell culture studies, molecular targets of chocolate polyphenols are endothelial nitric oxide synthetase as well as arginase. However, human bioavailability studies suggest that the plasma concentrations of cocoa polyphenols are manifold lower than those concentrations used in cultured cells in vitro. The experimental evidence for beneficial vascular effects of chocolate in human interventions studies is yet not fully convincing. Some human intervention studies on chocolate and its polyphenols lack a stringent study design. They are sometimes underpowered and not always placebo controlled. Dietary chocolate intake in many of these human studies was up to $100 \mathrm{~g}$ per day. Since chocolate is a rich source of sugar and saturated fat, it is questionable whether chocolate could be
\end{abstract}

G. Rimbach $(\bowtie)$

Institute of Human Nutrition and Food Science,

Christian-Albrechts-University, Kiel, Germany

e-mail: rimbach@foodsci.uni-kiel.de

\section{S. Egert}

Institute of Nutrition and Food Science, Nutritional Physiology, University of Bonn, Bonn, Germany

S. de Pascual-Teresa

Institute of Food Science, Food Technology and Nutrition

(ICTAN), CSIC, Madrid, Spain recommended as part of a nutrition strategy to promote vascular health.

Keywords Chocolate · Polyphenols · Procyanidins · Vascular health

Recent epidemiological studies suggest that chocolate may lower blood pressure and the incidence of cardiovascular diseases $[1,2]$. Chocolate is made out of cocoa which is a significant source of polyphenols including procyanidins. It is hypothesized that cocoa polyphenols activate endothelial nitric oxide synthase (eNOS) thereby increasing the concentration of vasodilative nitric oxide. L-arginine is the substrate of eNOS and arginase competes with eNOS for 1 -arginine as the common substrate. Thus, the concentration of 1-arginine is an important determinant for cellular NO production by eNOS [3]. Interestingly, it has been shown that cocoa polyphenols lower arginase-2 mRNA expression and activity in primary human endothelial cells [3]. In a recent cell culture study in endothelial cells, flavonoid (catechins, procyanidins) concentrations up to $100 \mu \mathrm{M}$ were used in order to increase nitric oxide levels in endothelial cells [4]. However, the plasma concentration of chocolate polyphenols is relatively low and often in the nanomolar range [5, 6]. Thus, the flavonoid concentrations, as used in cultured cells, may sometimes be un-physiologically high.

It has been suggested that cocoa-derived flavonoids may affect the production of proinflammatory mediators [7]. In general, flavonoids are often considered as potential antiinflammatory molecules $[8,9]$. However, in some studies, procyanidins, as present in cocoa, partly increased the production of tumor necrosis factor alpha and NF- $\kappa \mathrm{B}-$ dependent proinflammatory gene expression $[10,11]$. The 
chain length of procyanidins may have a significant effect on cytokine release [12].

Nevertheless, there are several short-term human intervention studies suggesting that chocolate may improve vascular health. The number of subjects included into these studies is often between fifteen [13] and forty-five volunteers [14] and thus these studies could be rather considered as pilot studies. A major concern with these small-scale human intervention studies is that they seem to be partly underpowered and many of these studies (not all) were not placebo controlled. Furthermore, several studies do not report plasma polyphenol concentrations in response to dietary chocolate intake. It is still unclear whether white chocolate is the right placebo? For example, white chocolate as a control food makes blinding of observers and participants impossible, thus increasing the risk of bias. In addition, white and dark chocolate have different compositions, which makes it difficult to identify the bioactive substance which is responsible for an effect on, e.g. endothelial function and/or blood pressure. White chocolate is made of cocoa butter, milk and sugar. It does not contain cocoa paste, liquor or powder. Thus, white chocolate lacks cocoa polyphenols, but it also lacks methylxanthines (e.g. caffeine), and has a different fatty acid and carbohydrate composition $[15,16]$. In order to reduce bias, the macroand micronutrient compositions as well as flavour and appearance of the "verum" and "placebo" need to be considered and strictly standardized in the design of a controlled clinical trial.

In several studies, up to $100 \mathrm{~g}$ chocolate per day were used in order to affect flow-mediated dilation, circulatory nitric oxide levels and ultimately blood pressure [17]. However, in the study by Taubert et al. [18], lower amounts of chocolate ( $\sim 6 \mathrm{~g}$ of dark chocolate per day) were used. It has been mentioned that the products used in controlled studies sometimes may contain higher polyphenol contents than commercially available products [19]. Polyphenols exhibit a bitter taste and some (not all) manufacturers have established processing technology for cocoa which eliminates the bitterness together with the polyphenols. Up to $90 \%$ of the polyphenols can be possibly lost during processing steps [20]. Thus, the food industry is encouraged to label the polyphenol content of chocolate.

In a recent meta-analysis on cocoa products and chocolate, a significant statistical heterogeneity across studies could be found [21], which may be also partly related to allelic variants in polyphenol-metabolizing enzymes. While in some studies dietary chocolate lowered blood pressure, in other studies no beneficial effect of chocolate on blood pressure could be observed. For instance, the double-blind, placebo-controlled, randomized trial by
Crews et al. [22] failed to support any beneficial effects of short-term dark chocolate and cocoa consumption on any of the cardiovascular health-related variables including blood pressure. Furthermore, consumption of dark chocolate and cocoa was associated with significantly higher pulse rates.

From a public health point of view, it may be still questionable whether we should increase the intake of dietary polyphenols due to chocolate. It is well known that chocolate is relatively high in sugar $(\sim 50 \mathrm{~g} / 100 \mathrm{~g})$ and saturated fatty acids ( $\sim 60 \%$ of total fatty acids); $100 \mathrm{~g}$ chocolate contains $480-540 \mathrm{kcal}$. Chronic unbalanced intake of chocolate may increase energy intake which in turn may increase body weight known to adversely affect blood pressure and vascular health. In a recent study, an increase in bodyweight $(0.8 \mathrm{~kg}$ over $3 \mathrm{month})$ due to the consumption of $25 \mathrm{~g}$ chocolate per day was evident [23]. Weight gain may also result in changes in metabolic parameters which in turn may counteract the blood pressure lowering effects of chocolate. It has been suggested by Desch et al. [21] that long-term "side effect profiles" of chocolate and its optimal dose need be established before any recommendations can be made [21]. Furthermore, it has been criticized that large-scale, well-controlled trials on chocolate with clinical endpoints are currently missing [23].

We should also take into account that chocolate is not the only source of procyanidins. We have conducted a systematic analysis of procyanidins in foodstuffs and beverages. Rich dietary sources of procyanidins are also several fruits including unpeeled apples, berries and plums to name a few [24]. If the procyanidin content of food items is calculated on energy basis, apples may contain more procyanidins per $\mathrm{kcal}(1.3 \mathrm{mg} / \mathrm{kcal})$ than chocolate $(0.9 \mathrm{mg} / \mathrm{kcal})$ [25].

While in terms of fruit and vegetable intake the motto "the more the better" may be valid, this seems to be not the case in terms of intake of chocolate mainly due to its high energy density. Another problem is that if we propose chocolate as a "healthy food item", the consumer may extrapolate such statements possibly also to other sweets and sugar-based food items. Since the prevalence of obesity has dramatically increased during the last decade, we should critically ask the question whether dietary recommendations in terms of chocolate and vascular health are practical at all? For the prevention and/or treatment of elevated blood pressure, well-established diet-related lifestyle modifications should be rather recommended and implemented, such as weight loss in overweight/obese patients, reduced salt intake and/or consumption of a diet rich in fruit and vegetables, rich in low-fat diary products and reduced in saturated fatty acids and cholesterol $[26,27]$. 


\section{References}

1. Buijsse B, Weikert C, Drogan D, Bergmann M, Boeing H (2010) Chocolate consumption in relation to blood pressure and risk of cardiovascular disease in German adults. Eur Heart $\mathbf{J}$ 31:1616-1623

2. Mostofsky E, Levitan EB, Wolk A, Mittleman MA (2010) Chocolate intake and incidence of heart failure: a populationbased, prospective study of middle-aged and elderly women. Circ Heart Fail 3:612-616

3. Schnorr O, Brossette T, Momma TY, Kleinbongard P, Keen CL, Schroeter H, Sies H (2008) Cocoa flavanols lower vascular arginase activity in human endothelial cells in vitro and in erythrocytes in vivo. Arch Biochem Biophys 476:211-215

4. Appeldoorn MM, Venema DP, Peters THF, Koenen ME, Arts ICW, Vincken JP, Gruppen H, Keijer J, Hollman PCH (2009) Some phenolic compounds increase the nitric oxide level in endothelial cells in vitro. J Agric Food Chem 57:7693-7699

5. Roura E, Andres-Lacueva C, Estruch R, Mata-Bilbao ML, Izquierdo-Pulido $\mathrm{M}$, Waterhouse AL, Lamuela-Raventos RM (2007) Milk does not affect the bioavailability of cocoa powder flavonoid in healthy human. Ann Nutr Metab 51:493-498

6. Murphy KJ, Chronopoulos AK, Singh I, Francis MA, Moriarty H, Pike MJ, Turner AH, Mann NJ, Sinclair AJ (2003) Dietary flavanols and procyanidin oligomers from cocoa (Theobroma cacao) inhibit platelet function. Am J Clin Nutr 77:1466-1473

7. Selmi C, Mao TK, Keen CL, Schmitz HH, Eric GM (2006) The anti-inflammatory properties of cocoa flavanols. J Cardiovasc Pharmacol 47(Suppl 2):S163-S171

8. Moini H, Rimbach G, Packer L (2000) Molecular aspects of procyanidin biological activity: disease preventative and therapeutic potentials. Drug Metabol Drug Interact 17:237-259

9. Saliou C, Valacchi G, Rimbach G (2001) Assessing bioflavonoids as regulators of NF-kappa B activity and inflammatory gene expression in mammalian cells. Methods Enzymol 335:380-387

10. Mao TK, van de Water J, Keen CL, Schmitz HH, Gershwin ME (2002) Modulation of TNF-alpha secretion in peripheral blood mononuclear cells by cocoa flavanols and procyanidins. Dev Immunol 9:135-141

11. Park YC, Rimbach G, Saliou C, Valacchi G, Packer L (2000) Activity of monomeric, dimeric, and trimeric flavonoids on NO production, TNF-alpha secretion, and NF-kappaB-dependent gene expression in RAW 264.7 macrophages. FEBS Lett 465:93-97

12. Kenny TP, Keen CL, Schmitz HH, Gershwin ME (2007) Immune effects of cocoa procyanidin oligomers on peripheral blood mononuclear cells. Exp Biol Med (Maywood) 232:293-300

13. Grassi D, Lippi C, Necozione S, Desideri G, Ferri C (2005) Short-term administration of dark chocolate is followed by a significant increase in insulin sensitivity and a decrease in blood pressure in healthy persons. Am J Clin Nutr 81:611-614
14. Faridi Z, Njike VY, Dutta S, Ali A, Katz DL (2008) Acute dark chocolate and cocoa ingestion and endothelial function: a randomized controlled crossover trial. Am J Clin Nutr 88:58-63

15. U.S. Department of Agriculture (2009) Composition of foods. Raw, processed, prepared. USDA National Nutrient Database for Standard Reference, Release 22

16. U.S. Department of Agriculture (2007) USDA Database for the flavonoid content of selected foods, Release 2.1

17. Grassi D, Necozione S, Lippi C, Croce G, Valeri L, Pasqualetti P, Desideri G, Blumberg JB, Ferri C (2005) Cocoa reduces blood pressure and insulin resistance and improves endotheliumdependent vasodilation in hypertensives. Hypertension 46:398-405

18. Taubert D, Roesen R, Lehmann C, Jung N, Schomig E (2007) Effects of low habitual cocoa intake on blood pressure and bioactive nitric oxide: a randomized controlled trial. JAMA 298:49-60

19. Rimbach G, Melchin M, Moehring J, Wagner AE (2009) Polyphenols from cocoa and vascular health-a critical review. Int J Mol Sci 10:4290-4309

20. Mehrinfar R, Frishman WH (2008) Flavanol-rich cocoa: a cardioprotective nutraceutical. Cardiol Rev 16:109-115

21. Desch S, Schmidt J, Kobler D, Sonnabend M, Eitel I, Sareban M, Rahimi K, Schuler G, Thiele H (2010) Effect of cocoa products on blood pressure: systematic review and meta-analysis. Am J Hypertens 23:97-103

22. Crews WD Jr, Harrison DW, Wright JW (2008) A double-blind, placebo-controlled, randomized trial of the effects of dark chocolate and cocoa on variables associated with neuropsychological functioning and cardiovascular health: clinical findings from a sample of healthy, cognitively intact older adults. Am J Clin Nutr 87:872-880

23. Desch S, Kobler D, Schmidt J, Sonnabend M, Adams V, Sareban M, Eitel I, Bluher M, Schuler G, Thiele H (2010) Low vs. higherdose dark chocolate and blood pressure in cardiovascular highrisk patients. Am J Hypertens 23:694-700

24. Pascual-Teresa S, Santos-Buelga C, Rivas-Gonzalo JC (2000) Quantitative analysis of flavan-3-ols in Spanish foodstuffs and beverages. J Agric Food Chem 48:5331-5337

25. Hammerstone JF, Lazarus SA, Schmitz HH (2000) Procyanidin content and variation in some commonly consumed foods. J Nutr 130:2086S-22092

26. Appel LJ, Brands MW, Daniels SR, Karanja N, Elmer PJ, Sacks FM (2006) Dietary approaches to prevent and treat hypertension: a scientific statement from the American Heart Association. Hypertension 47:296-308

27. Appel LJ, Giles TD, Black HR, Izzo JL Jr, Materson BJ, Oparil S, Weber MA (2010) ASH position paper: dietary approaches to lower blood pressure. J Am Soc Hypertens 4:79-89 